\title{
Does personality predict medical students' attitudes to learning communication skills?
}

\author{
Beatriz Molinuevo, Rafael Torrubia
}

Department of Psychiatry and Forensic Medicine, School of Medicine of the Universitat Autònoma de Barcelona, Spain

Correspondence: Beatriz Molinuevo Alonso, Unitat de Psicologia Mèdica, Departament de Psiquiatria i Medicina Legal

Facultat de Medicina, Universitat Autònoma de Barcelona, Campus de Bellaterra, s/n, 08193 Bellaterra, Spain

E-mail: Beatriz.Molinuevo@uab.cat

Accepted: July 28, 2013

\begin{abstract}
Objectives: To determine whether personality is related to medical students' attitudes towards learning communication skills and self-ratings on communication skills.

Methods: 524 first- and 507 second-year medical students completed the Communications Skills Attitudes Scale and rated their own communication skills. First-year students answered the Eysenck Personality Questionnaire, and second-year students the Zuckerman-Kuhlman Personality Questionnaire. Multiple regression analyses, controlling for gender, were conducted to study the impact of personality on attitudes. Analysis of variance followed by post hoc Duncan test was used to compare differences in personality traits depending on students' self-ratings on communication skills.
\end{abstract}

Results: After controlling for gender, personality traits predicted differences in attitudes and were significantly related to medical students' self-ratings. Medical students with higher scores on psychoticism or aggression-hostility showed worse attitudes. Students who tended to have a better self-image scored higher on extraversion, psychoticism, impulsive-sensation seeking, or aggression-hostility traits.

Conclusions: Findings support the consideration of personality traits for better student career guidance and counselling. Some students could have more difficulties to internalize certain healthcare professional competencies and show more resistance to attitude change.

Keywords: Attitudes, communication skills, medical students, personality traits

\section{Introduction}

One of the current debates in medical education is the inclusion of non-cognitive variables, such as personal qualities, in the selection procedure for future health professionals. ${ }^{1}$ There is a need to select the best candidates for medical schools not only because of the excess of applicants but also to develop competent and ethical health professionals. ${ }^{2-4}$ Becoming a good doctor is more than acquiring medical knowledge and using scientific and technical competencies, it is also essential to acquire interpersonal communication skills and professional behaviors. ${ }^{1,3}$

Traditionally, academic ability has been used as the main criterion; however, it is not as discriminating as previously thought. ${ }^{5}$ Medical students also differ according to their personality traits, interests, and motivations. Bore et al. ${ }^{4}$ have recently proposed a theoretical model for medical student selection that includes informed self-selection, academic achievement, general cognitive ability, personality characteristics, and interpersonal skills. Research is needed to determine which non-cognitive variables should be considered in the selection procedure of medical students. Studies of personality in medical students and practitioners have found that personality traits, especially conscientiousness, predict performance in medical school and future success in a medical career. ${ }^{6,7}$

For instance, personality distinguishes high competency from low-competency anesthesiology residents. ${ }^{8}$ Similarly, medical students' communication skills are positively related to personality characteristics such as warmth, emotional stability, and perfectionism. ${ }^{9}$ In addition, personality traits influence specialty choice of medical students, ${ }^{10,11}$ and discriminate among practitioners according to their medical specialty. ${ }^{12}$ However, despite the existing interest in personality, the wide variety of measures used and the 
absence of a recognized theoretical framework in the field of medical education make conclusions difficult. ${ }^{10,13}$

On the other hand, less is known about the relationship between personality traits and attitudes in medical education research. As students have prior attitudes towards the practice of medicine and the physician's role when admitted to medical school, ${ }^{14}$ certain attitudes could adversely affect the benefit the student can obtain during the medical training and negatively impact their future professional practice. At present, there is an international recognition of the importance of teaching communication skills during undergraduate medical training. ${ }^{15-17}$ However, students' attitudes towards learning communication skills differ according to gender or age. ${ }^{18}$ It remains unknown whether medical students' personalities have an impact on attitudes towards communication skills. If personality influences students' attitudes, the assessment of personality traits could also enable medical educators to formulate strategies for the best development of academic and clinical competence. ${ }^{19}$

The main aim of this study was to determine whether personality traits are related to medical students' attitudes towards learning communication skills. Based on prior work in the field of medicine about personality and other attitudes $^{19-21}$, we hypothesized that there would be a significant relationship. An additional goal was to analyze whether students' self-rated communication skills differ according to their personality traits. Because of lack of previous studies, no prediction was formulated. To provide data based on a robust and comprehensive model of personality, the aim was tested in two samples, first- and second-year medical students, with a different personality instrument in each one. Such findings would contribute to the literature on selection procedure of medical students and would provide empirical data for educators in a traditionally lesser known area of the medical curriculum, communication skills.

\section{Methods}

\section{Participants}

First-year and second-year medical students from the School of Medicine of the Universitat Autònoma de Barcelona (UAB) were invited to participate in the study. Students were in pre-clinical training. The first sample consisted of 524 first-year students ( 240 and 284 from 2009/10 and 2010/11 academic year, respectively). The second sample was composed of 507 second-year students (233 and 274, respectively). Participants represented $78.2 \%$ and $73.6 \%$ of the students enrolled, in that order. Demographic information is presented in Table 1.

\section{Measures}

\section{Demographic data}

Items about students' age, gender, country of origin, and parents' educational level were included.
Table 1. Demographic characteristics from 2009 to 2011 for firstand second-year medical students at the Autonomous University of Barcelona ( $\mathrm{N}=524$ and $\mathrm{N}=507$ respectively)

\begin{tabular}{|c|c|c|}
\hline Demographic characteristics & First-year & Second-year \\
\hline \multirow{3}{*}{ Age } & $\mathrm{M}(\mathrm{SD})$ & $M(S D)$ \\
\hline & $18.89(3.21)$ & $20.11(3.10)$ \\
\hline & n (\%) & $\mathrm{n}(\%)$ \\
\hline \multicolumn{3}{|l|}{ Gender } \\
\hline $\begin{array}{l}\text { Male } \\
\text { Female }\end{array}$ & $\begin{array}{l}178(34) \\
346(66)\end{array}$ & $\begin{array}{l}154(30) \\
352(70)\end{array}$ \\
\hline \multicolumn{3}{|l|}{ Country of origin } \\
\hline $\begin{array}{l}\text { Spain } \\
\text { Others }\end{array}$ & $\begin{array}{c}469(90) \\
54(10)\end{array}$ & $\begin{array}{c}430(85) \\
75(15)\end{array}$ \\
\hline \multicolumn{3}{|l|}{ Father's education } \\
\hline $\begin{array}{l}\text { None/unfinished primary } \\
\text { Compulsory secondary } \\
\text { High school graduate } \\
\text { College/university }\end{array}$ & $\begin{array}{c}26(5) \\
97(19) \\
108(21) \\
289(56)\end{array}$ & $\begin{array}{c}24(5) \\
79(16) \\
119(24) \\
282(56)\end{array}$ \\
\hline \multicolumn{3}{|l|}{ Mother's education } \\
\hline $\begin{array}{l}\text { None/unfinished primary } \\
\text { Compulsory secondary } \\
\text { High school graduate } \\
\text { College/university }\end{array}$ & $\begin{array}{c}21(4) \\
107(21) \\
120(23) \\
274(53)\end{array}$ & $\begin{array}{c}18(4) \\
93(19) \\
131(26) \\
262(52)\end{array}$ \\
\hline \multicolumn{3}{|l|}{ Self-ratings of communication skills } \\
\hline $\begin{array}{l}\text { Poor } \\
\text { Normal } \\
\text { Good } \\
\text { Excellent }\end{array}$ & $\begin{array}{c}7(1) \\
173(33) \\
309(59) \\
33(6)\end{array}$ & $\begin{array}{c}18(4) \\
189(37) \\
262(52) \\
37(7)\end{array}$ \\
\hline
\end{tabular}

Attitudes

The Communications Skills Attitudes Scale (CSAS) ${ }^{22}$ is an instrument designed to measure attitudes towards learning communication skills. The original items were created considering the views and experiences of five first-year medical students in a previous qualitative study. The original version consists of a two-factor scale with 13 items on each subscale, the Positive Attitudes Scale (PAS) (e.g., "In order to be a good doctor, I must have good communication skills") and the Negative Attitudes Scale (NAS) (e.g., "Nobody is going to fail their medical degree for having poor communication skills"). Items are scored from 1 (strongly disagree) to 5 (strongly agree). Higher scores indicate stronger attitudes. In this study, we used the Catalan version, ${ }^{23}$ which has shown satisfactory internal consistency and test-retest reliability.

Personality

The Eysenck Personality Questionnaire (EPQ $)^{24}$ is the result of more than 40 years of development and numerous psychometric and experimental studies in different countries. It is based on Eysenck's model of individual differences, ${ }^{25}$ one of the most outstanding theories in the scientific study of personality.

The EPQ is the most well-known and studied assessment instrument that measures the three broad dimensions of Eysenck's personality theory: extraversion-introversion (E), neuroticism-emotional stability $(\mathrm{N})$, and psychoticism (P). 
The first two appear to have universally been accepted. ${ }^{26-28}$ The dimension E includes traits such as sociability, liveliness, activity, assertiveness, sensation seeking, and expressiveness; the dimension $\mathrm{N}$ includes traits such as anxiety, unhappiness, guilt, low self-esteem, and shyness; and the dimension $\mathrm{P}$ describes traits such as low empathy, aggressiveness, egocentrism, impulsivity, and tough-mindedness. The EPQ also contains a Lie Scale (L) measuring dissimulation/conformity. The EPQ has generated substantial research in clinical, educational, experimental, occupational, and organizational psychology that has shown evidence of test reliability and validity. ${ }^{27}$ In this study, we used the Catalan adaptation of the short-version of the revised EPQ, the EPQ-RS. ${ }^{29}$ It contains a total of 48 dichotomous items (yes/no); 12 items, for each scale, including the Lie Scale.

The Zuckerman-Kuhlman Personality Questionnaire (ZKPQ) was developed within Zuckerman's Alternative Five Personality Model to measure basic personality traits with roots in biological traits. ${ }^{30}$ It contains five scales: 1) Impulsive-Sensation Seeking (ImpSS), describing a tendency to act quickly on impulse without planning, often in response to a need for thrills and excitement, change, and novelty; 2) Neuroticism-Anxiety (N-Anx) describes frequent emotional upset, tension, worry, fearfulness, indecision, lack of self-confidence, and sensitivity to criticism; 3) Aggression- Hostility (Agg-Host) describes a readiness to express verbal aggression, rude, thoughtless, or antisocial behavior, vengefulness and spitefulness, having a quick temper and impatience with others; 4) Activity (Act), describes a tendency to be active, to prefer challenging work, and being impatient or restless when there is nothing to do; and, 5) Sociability (Sy) describes a tendency to interact with others, preference for being with others, and intolerance of social isolation. The ZKPQ has shown good psychometric properties. ${ }^{30}$ In this study, we used the equivalent 50-item version, the ZKPQ-50-CC, ${ }^{31}$ which contains the five scales with five items each. Items are dichotomous (true/false). This short version presents psychometric properties strongly similar to the original version in different countries.

\section{Self-rating of communication skills}

In line with previous studies, ${ }^{22}$ we added the next question: How would you rate your present communication skills to practice as a future doctor? Answers were scored on a 4point scale ranging from 1 (poor) to 4 (excellent). The categories "poor" and "normal" were grouped together because of the low frequencies of the former (see Table 1). The final categories are "poor/normal," "good," and "excellent" (see Table 5).

\section{Procedure}

The samples were recruited in September 2009 and in September 2010. The instruments were administered by the authors in the students' classrooms. First-year medical Int J Med Educ. 2013;4:155-161 students completed the questionnaires on the first day of the course History of the Medicine, in three large groups of approximately 85 students each. Second-year medical students completed the questionnaires during the first seminar session of a course on communication skills in small groups of about 12 students each. As second-year medical students study a practical course about the EPQ, in order to avoid biases, the EPQ-RS was assigned to first-year students, and the ZKPQ-50-CC to second-year students.

Students were informed that participation was anonymous and voluntary, and no compensation was offered. Along with the questionnaire, students were given an information sheet about the study. This study was approved by the Animal and Human Experimentation Ethics Committee of the UAB.

\section{Data analysis}

Eighteen participants from the first-year sample (3.3\%) were excluded because their scores were higher than two standard deviations above the mean on the Lie scale from the EPQ. SPSS v15.0 was used for all analyses. Descriptive statistics (i.e., means and standard deviations) were computed for the scales of the diverse instruments (CSAS, EPQRS, ZKPQ-50-cc). Reliability (internal consistency) of all the scales was calculated with Cronbach's alpha. Gender differences in personality and attitudes were tested with Student's $\mathrm{t}$-test for independent samples, and effect size was measured with Cohen's d. ${ }^{32}$ Multiple regression analyses, controlling for gender, were conducted to study the impact of personality on attitudes. The independent variables were gender and the EPQ-RS and ZKPQ-50-cc scales (for first- and secondyear students, respectively), and the dependent variables were the Positive and Negative Attitudes scales of the CSAS. Gender was introduced in the first step with the method Enter and the personality variables in the second step with the stepwise procedure. Finally, an analysis of variance (ANOVA) followed by post hoc Duncan test was used to compare differences in personality traits depending on students' self-ratings of communication skills.

\section{Results}

\section{Descriptive statistics and reliability}

Means and standard deviations for the personality and attitude scales are displayed in Table 2. The internal consistency of the CSAS, EPQ-RS and ZKPQ-50-cc scales are shown in Table 2. The CSAS showed adequate reliability in both samples of students. The internal consistency of the Positive Attitudes scale was higher than that of the Negative Attitudes scale, as in previous studies. All the EPQ scales also showed adequate reliability, except for the Psychoticism scale, in which it was lower than 0.60. This scale has been criticized in part because of its internal reliability. All the scales of the ZKPQ-50-cc showed satisfactory alpha coefficients, similar to the Spanish adaptation, except for the Impulsive-Sensation Seeking scale $(\alpha=0.630)$. 
Table 2. Internal consistency and descriptive statistics of the CSAS, EPQ-RS and ZKPQ-50-cc from 2009 to 2011 for firstand second-year medical students at the Autonomous University of Barcelona ( $\mathrm{N}=524$ and $\mathrm{N}=507$ respectively)

\begin{tabular}{|c|c|c|c|c|c|c|c|}
\hline \multirow{2}{*}{\multicolumn{2}{|c|}{$\begin{array}{l}\text { Attitude / } \\
\text { Personality }\end{array}$}} & \multicolumn{3}{|c|}{ First-year } & \multicolumn{3}{|c|}{ Second-year } \\
\hline & & \multirow{2}{*}{$\frac{\alpha}{0.831}$} & \multirow{2}{*}{$\frac{M}{53.58}$} & \multirow{2}{*}{$\frac{S D}{5.50}$} & \multirow{2}{*}{$\frac{\alpha}{0.853}$} & \multirow{2}{*}{$\frac{M}{51.27}$} & \multirow{2}{*}{$\frac{S D}{6.30}$} \\
\hline$\infty$ & PAS & & & & & & \\
\hline ó & NAS & 0.681 & 23.87 & 4.41 & 0.616 & 25.51 & 4.45 \\
\hline \multirow{4}{*}{$\begin{array}{l}\infty \\
\frac{n}{1} \\
0 \\
0 \\
\frac{1}{\Psi}\end{array}$} & E & 0.780 & 9.29 & 2.69 & - & - & - \\
\hline & $N$ & 0.762 & 4.19 & 2.84 & - & - & - \\
\hline & $P$ & 0.557 & 2.01 & 1.74 & - & - & - \\
\hline & L & 0.595 & 5.40 & 2.47 & - & - & - \\
\hline \multirow{5}{*}{ 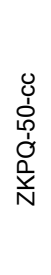 } & N-Anx & - & - & - & 0.757 & 3.22 & 2.53 \\
\hline & ImpSS & - & - & - & 0.630 & 6.34 & 2.22 \\
\hline & Act & - & - & - & 0.753 & 5.02 & 2.71 \\
\hline & Sy & - & - & - & 0.730 & 6.58 & 2.41 \\
\hline & Agg-Host & - & - & - & 0.628 & 4.38 & 2.31 \\
\hline
\end{tabular}

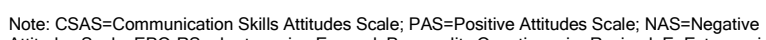
Attitudes Scale; EPQ-RS=short-version Eysenck Personality Questionnaire Revised; $E=E x$ traversion;

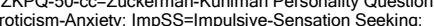
cross-Cultural short version; N-AnX-Neuroticism-Anxiety; Impsitity;
Act=Activity

\section{Gender differences in attitudes towards learning com- munication skills and personality traits}

Mean differences were found in all the instruments according to gender (see Table 3). Women scored significantly higher on positive attitudes towards learning communication skills and lower on negative attitudes compared with men in both samples, the effect sizes were medium, according to Cohen's d. Women had higher scores on the EPQ Neuroticism scale compared to men, and higher scores on the Lie scale; the effect size was medium in both cases. Women scored significantly higher on the ZKPQ Neuroticism-Anxiety scale, and men scored higher on the Aggression-Hostility scale. The effect sizes were medium and small, respectively.

The effect of personality traits on attitudes towards learning communication skills

In general, results from regression analyses showed that personality significantly predicted attitudes towards learning communication skills (Table 4). These findings were found in both samples, controlling for gender. In accordance with Eysenck's model, psychoticism was the most consistent predictor of differences in attitudes. Positive attitudes were firstly predicted by the Lie scale (positive relationship) and secondly by the Psychoticism scale (negative relationship). Negative attitudes firstly were predicted by higher scores on the Psychoticism scale and, secondly, by lower scores on the Extraversion scale. In Zuckerman's model, differences were only predicted by the
Aggression-Hostility scale, both in positive (negative relationship) and negative attitudes (positive relationship).

Differences in personality traits according to selfratings of communication skills

As seen in Table 5, self-ratings of communication skills were related to personality traits. In first-year students, statistically significant differences were found in two of the three personality scales of the EPQ, Extraversion and Psychoticism. Post hoc Duncan test showed that the three groups of self-rating of communication skills also differed in Extraversion; higher self-ratings were related to higher scores on the Extraversion scale, good self-ratings were related to medium scores, and poor/normal self-ratings were related to low scores. Students who rated themselves as having excellent communication skills scored higher on the Psychoticism scale compared with those who rated themselves as having poor/normal or good communication skills.

In second-year students, statistically significant differences were found in four of the five ZKPQ-50-cc scales: Impulsive-Sensation Seeking, Activity, Sociability, and Aggression-Hostility. Students who perceived themselves as having excellent communication skills scored higher on the Impulsive-Sensation Seeking scale in comparison to those who rated themselves as having poor/normal or good communication skills. Students who rated themselves as having excellent communication skills also scored higher on the Aggression-Hostility scale compared to the students who rated themselves as having poor/normal communication skills. The effect size in the Activity and Sociability scales was small, and the post hoc Duncan test found no group differences. Nevertheless, the results showed a tendency to score lower on these two personality scales in the group of students who rated themselves as having poor/normal communication skills.

\section{Discussion}

To our knowledge, this is the first study relating personality traits and medical students' attitudes towards learning communication skills and self-ratings of communication skills. Results showed that personality traits such as psychoticism, aggression-hostility, and extraversion predicted differences in medical students' attitudes. Higher P scores and lower E scores on the EPQ predict negative attitudes towards learning communication skills. Aggressionhostility predicts less positive attitudes and more negative attitudes towards learning communication skills. Another important finding was that students' self-ratings of communication skills differ according to personality traits such as extraversion, psychoticism, impulsive-sensation seeking, and aggression-hostility. Higher self-ratings were associated with higher P scores, higher ImpSS scores, and higher AggHost scores. Lower self-ratings were associated with lower Act and Sy scores. 
Table 3. Mean differences according to gender in the CSAS, EPQ-RS and ZKPQ-50-cc from 2009 to 2011 for first- and second-year medical students at the Autonomous University of Barcelona ( $\mathrm{N}=524$ and $\mathrm{N}=507$ respectively)

\begin{tabular}{|c|c|c|c|c|c|c|c|c|c|}
\hline \multirow{3}{*}{\multicolumn{2}{|c|}{$\begin{array}{l}\text { Attitude/ } \\
\text { Personality }\end{array}$}} & \multicolumn{3}{|c|}{ First-year } & \multicolumn{5}{|c|}{ Second-year } \\
\hline & & Men & Women & \multirow[b]{2}{*}{$t$} & \multirow[b]{2}{*}{$d$} & Men & Women & \multirow[t]{2}{*}{ 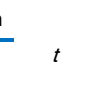 } & \multirow[b]{2}{*}{$d$} \\
\hline & & $\begin{array}{c}M \\
\text { (SD) }\end{array}$ & $\begin{array}{c}M \\
\text { (SD) }\end{array}$ & & & $\begin{array}{c}M \\
(\mathrm{SD})\end{array}$ & $\begin{array}{c}M \\
(\mathrm{SD})\end{array}$ & & \\
\hline \multirow{2}{*}{ क्ष } & PAS & $\begin{array}{l}52.44 \\
(5.72)\end{array}$ & $\begin{array}{l}54.14 \\
(5.31)\end{array}$ & $-3.36^{* *}$ & 0.29 & $\begin{array}{l}49.14 \\
(6.85)\end{array}$ & $\begin{array}{l}52.18 \\
(5.80)\end{array}$ & $-5.12^{* * *}$ & 0.48 \\
\hline & NAS & $\begin{array}{l}25.38 \\
(4.53)\end{array}$ & $\begin{array}{l}23.13 \\
(4.17)\end{array}$ & $5.63^{\mathrm{nx}}$ & 0.51 & $\begin{array}{l}27.05 \\
(4.97) \\
\end{array}$ & $\begin{array}{l}24.86 \\
(4.03)\end{array}$ & $4.77^{\mathrm{x*x}}$ & 0.48 \\
\hline \multirow{4}{*}{$\begin{array}{l}0 \\
\frac{n}{1} \\
0 \\
\frac{1}{4}\end{array}$} & $\mathrm{E}$ & $\begin{array}{c}9.19 \\
(2.78)\end{array}$ & $\begin{array}{c}9.34 \\
(2.66)\end{array}$ & -0.59 & & & & & \\
\hline & $\mathrm{N}$ & $\begin{array}{c}3.51 \\
(2.79)\end{array}$ & $\begin{array}{c}4.54 \\
(2.81)\end{array}$ & $-3.99^{9 m x}$ & 0.37 & & & & \\
\hline & $P$ & $\begin{array}{c}2.20 \\
(1.78)\end{array}$ & $\begin{array}{c}1.91 \\
(1.71)\end{array}$ & 1.81 & & & & & \\
\hline & L & $\begin{array}{c}4.84 \\
(2.31)\end{array}$ & $\begin{array}{c}5.68 \\
(2.50)\end{array}$ & $-3.75^{\operatorname{mx} x}$ & 0.35 & & & & \\
\hline \multirow{5}{*}{$\begin{array}{l}0 \\
0 \\
0 \\
0 \\
0 \\
0 \\
\frac{1}{N} \\
\text { N }\end{array}$} & N-Anx & - & - & - & & $\begin{array}{c}2.29 \\
(2.15)\end{array}$ & $\begin{array}{c}3.63 \\
(2.58)\end{array}$ & $-6.05^{* * *}$ & 0.56 \\
\hline & ImpSS & - & - & - & & $\begin{array}{c}6.63 \\
(2.13)\end{array}$ & $\begin{array}{c}6.20 \\
(2.25)\end{array}$ & 1.99 & \\
\hline & Act & - & - & - & & $\begin{array}{c}5.23 \\
(2.72)\end{array}$ & $\begin{array}{c}4.93 \\
(2.72)\end{array}$ & 1.13 & \\
\hline & Sy & - & - & - & & $\begin{array}{c}6.45 \\
(2.61)\end{array}$ & $\begin{array}{c}6.63 \\
(2.33)\end{array}$ & -0.79 & \\
\hline & $\begin{array}{l}\text { Agg- } \\
\text { Host }\end{array}$ & - & - & - & & $\begin{array}{c}4.70 \\
(2.24)\end{array}$ & $\begin{array}{c}4.23 \\
(2.33)\end{array}$ & $2.11^{\circ}$ & 0.21 \\
\hline
\end{tabular}

Note: $\mathrm{CSAS}=$ Communication Skills Attitudes Scale; PAS = Positive Attitudes Scale; NAS=Negative Attitudes Scale; EPQ-RS=short-version Eysenck Personality Questionnaire Revised; E=Extraversion; N=Neuroticism; P=Psychoticism; L=Lie; ZKPQ-50-cc=Zuckerman-Kuhlman Personality Questionnaire cross-cultural short version; N-Anx=Neuroticism-Anxiety; ImpSS=Impulsive-Sensation Seeking; Act= Activity; Sy=Sociability; Agg-Host=Aggression-Hostility.

Activity; Sy=Sociability; Agg-

Overall, personality traits had more impact on negative attitudes towards learning communication skills compared to positive attitudes. This fact is probably related to the influence of social desirability on positive attitudes, as observed in the sample of first-year medical students whose higher L scores predicted positive attitudes. The impact of personality traits on attitudes towards learning communication skills was small. Nevertheless, it is important to note the consistency of the results across two large samples of medical students and two different personality questionnaires (the EPQ-RS and the ZKPQ-50-CC), both based on the trait approach to personality. These results encourage using personality traits to improve student's career guidance and counselling.

High scores in the Psychoticism scale of the EPQ-RS are usually related to lack of empathy, cruelty, impulsiveness, hostility, aggressiveness, emotional indifference, socialization deficit, and psychopathy, and low scores in the Extraversion scale are related to introspection, calmness and less sociability. ${ }^{28}$ Both high $\mathrm{P}$ scores and low $\mathrm{E}$ scores predict negative attitudes towards learning communication skills. Individuals scoring high on the Aggression-Hostility scale of the ZKPQ-50-CC are commonly described as having a predisposition to express verbal aggression and showing rudeness, thoughtlessness, vengefulness, spitefulness, quick temper and impatient behavior. ${ }^{10}$ Psychoticism and Aggression-Hostility scales, although belonging to different personality instruments, are positively and significantly related. ${ }^{33}$ Coherently, in this study, medical students' with personality traits characterized by lack of socialization and low empathy presented worse attitudes towards learning communication skills. This finding suggests that personality influences students' concept of professionalism independently of external information. Future research should explore whether attitudes can be changed in students scoring high on psychoticism and aggression-hostility.

Table 4. Summary of regression analyses about prediction attitudes towards learning communication skills in medical students from personality traits from 2009 to 2011 for first- and second-year medical students at the Autonomous University of Barcelona ( $\mathrm{N}=524$ and $\mathrm{N}=507$ respectively)

\begin{tabular}{|c|c|c|c|}
\hline \multirow{2}{*}{$\begin{array}{l}\text { Attitude/ } \\
\text { Personality }\end{array}$} & \multicolumn{2}{|l|}{$\begin{array}{l}\text { Positive } \\
\text { attitudes }\end{array}$} & $\begin{array}{l}\text { Negative } \\
\text { attitudes }\end{array}$ \\
\hline & \multicolumn{2}{|l|}{$\beta\left(\Delta R^{2}\right)$} & $\beta\left(\Delta R^{2}\right)$ \\
\hline \multicolumn{4}{|c|}{ EPQ-RS (first-year medical students) } \\
\hline Step 1(enter) & & Step 1(enter) & \\
\hline Gender & $0.11^{*}(1.9 \%)$ & Gender & $-0.22^{* \star *}(5.6 \%)$ \\
\hline $\begin{array}{l}\text { Step } 2 \\
\text { (stepwise) }\end{array}$ & & $\begin{array}{l}\text { Step } 2 \\
\text { (stepwise) }\end{array}$ & \\
\hline Lie & $0.13^{* *}(2.0 \%)$ & Psychoticism & $0.16^{* * t}(2.2 \%)$ \\
\hline Psychoticism & $-0.09^{*}(0.8 \%)$ & Extraversion & $-0.12^{* *}(1.3 \%)$ \\
\hline
\end{tabular}

ZKPQ-50-cc (second-year medical students)

\begin{tabular}{llll} 
Step 1(enter) & \multicolumn{3}{c}{ Step 1(enter) } \\
Gender & $0.21^{* * *}(5.0 \%)$ & $\begin{array}{l}\text { Gender } \\
\text { Step 2 }\end{array}$ & $-0.21^{* * *}(5.1 \%)$ \\
$\begin{array}{l}\text { (stepwise) } \\
\text { Aggression- }\end{array}$ & $-0.12^{* *}(1.3 \%)$ & $\begin{array}{l}\text { Step 2 } \\
\text { (stepwise) }\end{array}$ & $\begin{array}{l}\text { Aggression- } \\
\text { Hostility }\end{array}$ \\
Hostility & & $0.17^{* * *}(2.8 \%)$ \\
\hline
\end{tabular}

Note: $C S A S=C o m m u n i c a t i o n$ Skills Attitudes Scale; EPQ-RS=short-version Eysenck Personality Questionnaire Revised; ZKPQ-50-cc=Zuckerman-Kuhlman Personality Questionnaire cross-cultural short version. Gender ( $0=$ Men, $1=$ Women) $p<0.05,{ }^{* \star} p<0.01, \quad p<0.001$

Extraversion involves being sociable, lively, active, assertive, sensation-seeking, carefree, dominant, surgent, and venturesome. ${ }^{29}$ The amount of time extraverts spend socializing helps them to train communication skills and to acquire high social competencies. ${ }^{34}$ This study did not examine medical students' real communication skills, but it does show that higher scores in Extraversion are related to students' higher self-ratings of communication skills. The profession of Medicine involves interacting with others, and high extraversion may be helpful. The personality dimension Extraversion may influence medical students' selfimage of their interpersonal competence, which, in turn, could influence their satisfaction with some clinical tasks and their future specialty choice. Future research should determine whether introverts are more interested in obtaining additional training in communication skills and professional orientation compared to extraverts. This information would be useful to medical educators to early ameliorate the potential of some students who wish to become competent professionals but who have some previous personal difficulties. 
Surprisingly, students with high scores in psychoticism and aggression-hostility perceive themselves as having excellent communication skills compared to those with low scores. As characteristics that describe these traits are not associated with acceptable social behavior, a possible explanation for this finding is that these personality traits interfere negatively with students' insight of their interpersonal skills. If this is supported, students with certain personality traits could enter into a negative vicious circle that would prevent them from improving their communication skills and changing cognitive biases. Future research is needed to examine whether students' self-ratings of communication skills are positively related to their real abilities.

Table 5. Mean differences in personality according to self-ratings in communication skills (ANOVA and Duncan's test) from 2009 to 2011 for first- and second-year medical students at the Autonomous University of Barcelona ( $\mathrm{N}=524$ and $\mathrm{N}=507$ respectively)

\begin{tabular}{|c|c|c|c|c|c|}
\hline \multirow[b]{2}{*}{ Personality } & \multicolumn{5}{|c|}{ Self-rating of communication skills } \\
\hline & $\begin{array}{c}\text { Poor/ } \\
\text { Normal } \\
(1)\end{array}$ & $\begin{array}{l}\text { Good } \\
(2)\end{array}$ & $\begin{array}{l}\text { Excellent } \\
\text { (3) }\end{array}$ & $F$ & Duncan \\
\hline EPQ-RS & \multicolumn{5}{|c|}{ First-year medical students } \\
\hline Extraversion & $\begin{array}{l}8.28 \\
(2.85)\end{array}$ & $\begin{array}{c}9.73 \\
(2.49)\end{array}$ & $\begin{array}{l}10.61 \\
(2.06)\end{array}$ & $22.14^{\mathrm{n \pi x}}$ & $1<2<3$ \\
\hline Neuroticism & $\begin{array}{c}4.54 \\
(3.08)\end{array}$ & $\begin{array}{c}4.01 \\
(2.65)\end{array}$ & $\begin{array}{c}4.18 \\
(3.08)\end{array}$ & 1.96 & \\
\hline Psychoticism & $\begin{array}{l}1.97 \\
(1.65)\end{array}$ & $\begin{array}{l}1.96 \\
(1.71)\end{array}$ & $\begin{array}{l}2.76 \\
(2.31)\end{array}$ & $3.23^{*}$ & $1,2<3$ \\
\hline Lie & $\begin{array}{c}5.27 \\
(2.38)\end{array}$ & $\begin{array}{c}5.52 \\
(2.53)\end{array}$ & $\begin{array}{c}5.00 \\
(2.31)\end{array}$ & 1.08 & \\
\hline ZKPQ-50-cc & \multicolumn{5}{|c|}{ Second-year medical students } \\
\hline $\begin{array}{l}\text { Neuroticism- } \\
\text { Anxiety }\end{array}$ & $\begin{array}{c}3.41 \\
(2.69)\end{array}$ & $\begin{array}{c}3.09 \\
(2.40)\end{array}$ & $\begin{array}{c}3.11 \\
(2.55)\end{array}$ & 0.96 & \\
\hline $\begin{array}{l}\text { Impulsive- } \\
\text { Sensation Seeking }\end{array}$ & $\begin{array}{c}6.03 \\
(2.33)\end{array}$ & $\begin{array}{c}6.45 \\
(2.09)\end{array}$ & $\begin{array}{c}7.24 \\
(2.15)\end{array}$ & $5.50^{\pi *}$ & $1,2<3$ \\
\hline Activity & $\begin{array}{l}4.60 \\
(2.72)\end{array}$ & $\begin{array}{l}5.30 \\
(2.67)\end{array}$ & $\begin{array}{l}5.38 \\
(2.81)\end{array}$ & $4.21^{*}$ & \\
\hline Sociability & $\begin{array}{c}6.21 \\
(2.57)\end{array}$ & $\begin{array}{l}6.86 \\
(2.19)\end{array}$ & $\begin{array}{c}6.62 \\
(2.80)\end{array}$ & $4.20^{*}$ & \\
\hline $\begin{array}{l}\text { Aggression- } \\
\text { Hostility }\end{array}$ & $\begin{array}{c}4.01 \\
(2.37)\end{array}$ & $\begin{array}{c}4.55 \\
(2.21)\end{array}$ & $\begin{array}{l}5.23 \\
(2.39)\end{array}$ & $5.87^{* *}$ & $1<3$ \\
\hline
\end{tabular}

Note: EPQ-RS =short-version Eysenck Personality Questionnaire Revised; ZKPQ-50cc=Zuckerman-Kuhlman Personality Questionnaire cross-cultural short version. $p<0.05,{ }^{*} p<0.01, p<0.001$

Finally, although not a main goal of the study, it is important to note the relevance of the variable gender. In line with prior research, students' attitudes differ according to gender, that is, females show more positive attitudes towards learning communication skills compared to males. In addition, consistent with earlier findings, there were also differences in personality traits. ${ }^{35,36}$ However, gender, which was entered in the multiple regression analysis in the first step, explained more variation in attitudes than did personality traits, suggesting that gender is more relevant to positive attitude development than students' personality. This result is consistent with the consideration of gender as a main physician's sociodemographic characteristic that significantly affects communication in medical visits. ${ }^{37}$ Nevertheless, gender does not annul the effect of personality traits.

These results should be interpreted taking into account some limitations. First, the inclusion of students from a single institution limits any generalizations; however, we used two samples and two different instruments. Second, the inclusion of two consecutive academic courses implies that approximately one half of the second-year students (course 2010-2011) were also in the first-year sample (course 2009-2010). This fact can overestimate the consistency of the results in the two samples. Nevertheless, there was a minimum of 233 students in each participating class, which is large enough to consider the robustness of the data. Third, students' self-rating of communication skills only included one item. However, it is a general question that has been used in prior work. Future research could explore students' self-ratings of specific communication skills.

In conclusion, this study confirms the influence of personality traits on medical students' attitudes towards learning communication skills and self-ratings of communication skills. Although the effect size on attitudes is small, the data suggest that there is a subgroup of students who may have more difficulties to internalize certain professional healthcare competencies and may be more resistant to changing their attitudes. ${ }^{38}$ The assessment of personality could be useful for medical educators to detect the students who may be vulnerable to presenting cognitive, emotional, and social deficits that can negatively impact their medical training and future clinical practice.

\section{Acknowledgements}

The authors wish to thank the students who participated in this study, Toni Cañete for his help in entering study data into SPSS, and our colleagues from the School of Medicine who helped us to collect the data.

\section{Conflict of Interest}

The authors declare that they have no conflict of interest.

\section{References}

1. Powis D. Personality testing in the context of selecting health professionals. Medical Teacher. 2009;31(12):1045-6.

2. Prideaux D, Roberts C, Eva K et al. Assessment for selection for the health care professions and specialty training: consensus statement and recommendations from the Ottawa 2010 conference. Medical Teacher. 2011;33 (3):215-23.

3. Lumsden MA, Bore M, Millar K, Jack R, Powis D. Assessment of personal qualities in relation to admission to medical school. Medical Education. 2005;39(3):258-65.

4. Bore M, Munro D, Powis D. A comprehensive model for the selection of medical students. Medical Teacher. 2009;31(12):1066-72.

5. Morrison J. How to choose tomorrow's doctors. Medical Education. 2005; 39(3):240-2.

6. Doherty EM, Nugent E. Personality factors and medical training: a review of the literature. Medical Education. 2011;45(2):132-40. 
7. Tartas M, Walkiewicz M, Majkowicz M, Budzinski W. Psychological factors determining success in a medical career: a 10-year longitudinal study. Medical Teacher. 2011;33(3):e163-72.

8. Merlo LJ, Matveevskii AS. Personality testing may improve resident selection in anesthesiology programs. Medical Teacher. 2009;31(12):e551-4. 9. Manuel RS, Borges NJ, Gerzina HA. Personality and clinical skills: any correlation? Academic Medicine. 2005;80(10):S30-3.

10. Hojat M, Zuckerman M. Personality and specialty interest in medical students. Medical Teacher. 2008;30(4):400-6.

11. Vaidya NA, Sierles FS, Raida MD, Fakhoury FJ, Przybeck TR, Cloninger CR. Relationship between specialty choice and medical student temperament and character assessed with Cloninger inventory. Teaching and Learning in Medicine. 2004;16(2):150-6.

12. Borges NJ, Osmon WR. Personality and medical specialty choice: technique orientation versus people orientation. Journal of Vocational Behavior. 2001;58(1):22-35.

13. Ferguson E, James D, Madeley L. Factors associated with success in medical school: systematic review of the literature. British Medical Journal. 2002;324(7343):952-7.

14. Woloschuk W, Harasym PH, Temple W. Attitude change during medical school: a cohort study. Medical Education. 2004;38(5):522-34.

15. Makoul G. Essential elements of communication in medical encounters: the Kalamazoo consensus statement. Academic Medicine. 2001;76(4):390-3. 16. von Fragstein M, Silverman J, Cushing A, Quilligan S, Salisbury H, Wiskin C. UK consensus statement on the content of communication curricula in undergraduate medical education. Medical Education. 2008;42(11):1100-7.

17. General Medical Council. Tomorrow's doctors. Outcomes and standards for undergraduate medical education. London: General Medical Council; 2009 .

18. Rees C, Sheard C. The relationship between medical students' attitudes towards communication skills learning and their demographic and education-related characteristics. Medical Education. 2002;36(11):1017-27. 19. Plaisant O, Courtois R, Toussaint PJ, Mendelsohn GA, John OP, Delmas $\mathrm{V}$, et al. Medical students' attitudes toward the anatomy dissection room in relation to personality. Anatomical Science Education. 2011;4(6):305-10.

20. Katz RS. Personality trait correlates of attitudes toward older people. International Journal of Aging and Human Development. 1990;31(2):14759.

21. Karl KA, Peluchette JV, Harland L. Is fun for everyone? Personality differences in healthcare providers' attitudes toward fun. Journal of Health and Human Services Administration. 2007;29(4):409-47.

22. Rees C, Sheard C, Davies S. The development of a scale to measure medical students' attitudes towards communication skills learning: the communication skills attitude scale (CSAS). Medical Education. 2002;36 (2):141-7.

23. Molinuevo B, Torrubia R. Validation of the Catalan version of the communication skills attitude scale (CSAS) in a cohort of south European medical and nursing students. Education for Health. 2011;24(1):1-13.
24. Eysenck HJ, Eysenck SBG. Manual of the Eysenck personality scales. London: Hodder \& Stoughton; 1991.

25. O'Connor KP. Eysenck's model of individual differences. In: Boyle GJ, Matthews G, Saklofske DH, editors. The SAGE handbook of personality theory and assessment, Vol 1: Personality theories and models. Thousand Oaks, CA: Sage Publications, Inc; 2008.

26. Boyle GJ. Critique of the five-factor model of personality. In: Boyle GJ, Matthews G, Saklofske DH, Boyle GJ, Matthews G, Saklofske DH, editors. The SAGE handbook of personality theory and assessment, Vol 1: Personality theories and models. Thousand Oaks, CA: Sage Publications, Inc; 2008. 27. Furnham A, Eysenck SBG, Saklofske DH. The Eysenck personality measures: fifty years of scale development. In: Boyle GJ, Matthews G, Saklofske DH, editors. The SAGE handbook of personality theory and assessment, Vol 2: Personality measurement and testing. Thousand Oaks, CA: Sage Publications, Inc; 2008.

28. Eysenck HJ. The definition and measurement of psychoticism. Personality and Individual Differences. 1992;13(7):757-85.

29. Eysenck HJ, Eysenck SBG. EPQ-R. Cuestionario revisado de personalidad de Eysenck. Versiones completa (EPQ-R) y abreviada (EPQ-RS). $2^{\text {nd }}$ ed. Madrid: TEA Ediciones; 2001.

30.Zuckerman M. Zuckerman-Kuhlman personality questionnaire (ZKPQ): An operational definition of the alternative five factorial model of personality. In: Boyle GJ, Matthews G, Saklofske DH, editors. The SAGE handbook of personality theory and assessment, $\mathrm{Vol} 2$ : Personality measurement and testing. Thousand Oaks, CA: Sage Publications, Inc; 2008.

31. Aluja A, Rossier J, García LF, Angleitner A, Kuhlman M, Zuckerman M. A cross-cultural shortened form of the ZKPQ (ZKPQ-50-cc) adapted to English, French, German, and Spanish languages. Personality and Individual Differences. 2006;41(4):619-28.

32. Cohen J. A power primer. Psychological Bulletin. 1992;112(1):155-9.

33. Aluja A, García O, García LF. Replicability of the three, four and five Zuckerman's personality super-factors: exploratory and confirmatory factor analysis of the EPQ-RS, ZKPQ and NEO-PI-R. Personality and Individual Differences. 2004;36(5):1093-108.

34. Friedman HS, Kern ML, Reynolds CA. Personality and health, subjective well-being, and longevity. Journal of Personality. 2010;78(1):179-216.

35. Fanous A, Gardner CO, Prescott CA, Cancro R, Kendler KS. Neuroticism, major depression and gender: a population-based twin study. Psychological Medicine. 2002;32(4):719-28.

36. Gomà-I-Freixanet $M$, Valero $S$, Punti J, Zuckerman M. Psychometric properties of the Zuckerman-Kuhlman personality questionnaire in a Spanish sample. European Journal of Psychological Assessment. 2004;20(2) :134-46.

37. Roter DL, Hall, JA. Doctors talking with patients/patients talking with doctors, 2nd ed. Westport, CT: Praeger; 2006.

38. Westmoreland GR, Counsell SR, Sennour Y, Schubert CC, Frank KI, Wu J, et al. Improving medical student attitudes toward older patients through a "council of elders" and reflective writing experience. Journal of the American Geriatric Society. 2009;57(2):315-20. 